Session 2175

\title{
Handling Hazardous Materials: The integration of chemical concepts with practical applications in the industrial workplace for engineering and science majors
}

\author{
Daryl J. Doyle \\ Professor of Chemistry, Kettering University, Flint, MI 48504
}

The Chemistry discipline at Kettering University offers CHEM-271, Handling Hazardous Materials, as an elective for both science and engineering majors. The prerequisites for this course are two terms of chemistry one of which must contain fundamentals of organic chemistry. The topics covered by this course are not found in any other elective course taken by students at Kettering University. Since this course is not a prerequisite for any other course offered at Kettering University, the coverage of the course varies from term to term depending upon the make of the student body in the class and the students' interests. The textbook used in the course is Chemical Process Safety, Fundamental with Applications by Crowl and Louvar ${ }^{1}$. Since Kettering University does not offer a chemical engineering degree, only certain portions of the text are used. Topics that are typically covered include:

1) Review of inorganic and organic chemical principles

2) Toxicology

3) Industrial hygiene

4) Toxic release and dispersion models

5) Fires and explosions

6) Inerting

7) Static electricity

8) Risk and risk analysis

9) Accidents and their investigations

The first portion of the course is a review of basic inorganic and organic chemistry. This is necessary because most of the students in the class are juniors or seniors and have not directly used chemical principles for two or three years. This review is based on practical applications of fundamental chemistry to real-world problems. Once this review is finished, various chapters from the textbook are covered. What follows are several examples of questions that are representative of those used in the course to apply chemical principles to various topics in the course.

A manufacturer uses MEK, methyl ethyl ketone, as a solvent. "Empty" 55-gallon barrels are returned to the supplier to be reused. On average, 0.75 inch of solvent is left in each "empty" barrel. In order to do a mass balance of solvent use and emission to the atmosphere, it is important to know how much is returned to the supplier. How many pounds of MEK are returned in each "empty" barrel? (Used in review of chemical principles) 
To solve this problem the following concepts are used:

a) Organic nomenclature and organic functional groups

b) Unit analysis

c) Density and specific gravity of liquids (obtained from MSDS at www.hazard.com)

d) Volume of a cylinder

e) Estimation of the dimensions of a 55-gallon barrel

A vendor indicates that a Stoddard Solvent (used in testing of fuel pumps and fuel injectors) has a requirement that not less than $50 \%$ of the solvent distills at $350^{\circ} \mathrm{F}$ and has a dry endpoint not above $410^{\circ} \mathrm{F}$. What are these temperatures on the Celsius, Kelvin, and Rankin scales? (Used in review of chemical principles)

To solve this problem the students need to understand the relationships between the temperature scales. Many students (for example, the science majors) have never used the Rankin scale even though it is used in engineering.

What is the density of dry air? What is the density of carbon dioxide? What potential danger exists if dry ice is used in an industrial setting? (Used in review of chemical principles)

The concepts used to solve this problem include:

a) Composition of dry air by volume percent

b) Ideal gas law including the measurement of pressure

c) Unit conversions

A gallon of methanol is spilled in a non-ventilated room. How many cubic feet of vapor will be generated given the molar mass of methanol is 32 grams per mole and has a specific gravity of 0.792 . Assume $70^{\circ} \mathrm{F}$ and $740 \mathrm{~mm} \mathrm{Hg}$. (Used in review of chemical principles)

The concepts used to solve this problem are:

a) Ideal gas law

b) Unit conversions

c) Pressure conversions

d) Temperature conversions

What is the normality of 0.1 Molar $\mathrm{H}_{2} \mathrm{SO}_{4}$ solution? (Used in chemical review. Most freshmen chemistry textbooks no longer cover the concept of normality yet it is used in the engineering field and may appear on the Fundamental of Engineering Exam, the first step toward becoming a registered engineer.)

The Department of Transportation (DOT) regulations state that a solution must be labeled as corrosive if it has a $\mathrm{pH}$ that is less than 2 or greater than 12.5 . Is a $0.5 \%$, by mass, sodium hydroxide solution considered corrosive? (Used in review of chemical principles) 
Concepts used to solve this problem include:
a) Grams to moles conversions
b) Molarity
c) $\mathrm{pH}$

In preparing for the worst case scenario in an industrial setting, it is determined that a 4$\mathrm{kg}$ bottle of concentrated hydrochloric acid could be spilled. The MSDS states that sodium carbonate can be used to neutralize a spill of hydrochloric acid. What mass of sodium carbonate needs to be in the spill kit in the event of spill? (Used in chemical review)

The following concepts are required to solve this problem:

a) Inorganic nomenclature

b) Writing acid/base reactions and balancing them

c) Grams to mole conversion

d) Unit analysis

The upper respiratory tract is attacked by water-soluble compounds and the lower respiratory tract is attacked by water-insoluble compounds. List several organic and inorganic compounds that are water-soluble and water-insoluble. (Used in toxicology section of course)

Threshold limit values (TLV) and permissible exposure limits (PEL) are usually given in parts per million (PPM) yet many calculations result in concentration of gases in milligrams per cubic meter. The PEL for benzene is 1 PPM. What is this concentration in milligrams per cubic meter? (Used in toxicology section of course)

To solve this problem the following concepts required:

a) Names of common organic compounds

b) Ideal gas equation

c) Unit analysis

The rate of metabolism for a certain toxicant in the body is known to be first order. At 1:00 PM the level of toxicant in a patient's blood was measured to be $3.5 \mathrm{mg} / \mathrm{L}$. At 2:45 PM the concentration had fallen to $1.89 \mathrm{mg} / \mathrm{L}$. What is the half-life of this toxicant in the body? When would the concentration be expected to reach $0.05 \mathrm{mg} / \mathrm{L}$ ? How much toxicant would be in the blood 50 hours after the first reading was taken. (Used in the toxicology section of the course.)

To solve this problem the student must understand first order chemical kinetics.

What is the vapor pressure of methanol in an enclosed tank above a solution that is $25 \%$ water and $75 \%$ methanol, by mass, and is at $80^{\circ} \mathrm{C}$ ? (Used in the industrial hygiene portion of the course.) 
To solve this problem the following concepts are required:

a) Antoine's Equation for vapor pressures of liquids at temperature other than room temperature.

b) Raoult's Law

c) Dalton's Law of partial pressures

What is the mass percent of acetone in a solution composed of a combination of water and acetone? The flash point of the solution is $38^{\circ} \mathrm{C}$. (Used in the fires and explosions section of the course)

The following concepts are required to solve this problem:
a) Antoine's equation
b) Raoult's law
c) Unit conversions

What are the lower flammable limit and the upper flammable limit of a gaseous mixture that has a carbon monoxide pressure of 75 torr and a methane pressure of 150 torr in a container that has a total pressure of 750 torr? (Used in the fires and explosions section of the course)

To solve this problem the following chemical concepts are used:

a) Dalton's law of partial pressure

b) Mole fraction in gas phase

What is the lower flammability limit for methanol at $75^{\circ} \mathrm{C}$ given the thermodynamic tables? (Used in the fires and explosion portion of the course)

The solution to this problem involves the heat of combustion of methanol. Therefore, writing and balancing combustion reactions and the calculation of $\Delta \mathrm{H}_{\text {combustion }}$ are required.

Assume that you are in charge of the decontamination of a large office building that has been found to be contaminated with anthrax spores. The method involves the use of ethylene oxide vapor. The Slovanft Corporation of Slovakia (a real company with a web site) offers ethylene oxide that is $99.9 \%$ pure in $65 \mathrm{~m}^{3}$ containers that are $90 \%$ full of liquid. Since ethylene oxide is very explosive, 0.35 megapascals of nitrogen gas is placed in the headspace of the tank. The containers are shipped at $-5^{\circ} \mathrm{C}$. What is the limiting oxygen concentration (LOC) for ethylene oxide? Assume that a $65-\mathrm{m}^{3}$ tank of ethylene oxide vaporizes and explodes. Estimate the equivalent tons of TNT that this explosion would generate? (Used in the fires and explosions portion of the course)

The solution to this set of problems include using the following:

a) Writing and balancing the combustion reaction of ethylene oxide

b) Using thermodynamic tables to determine the heat of combustion of ethylene. (Actually the determination of Gibbs free energy is the 
correct method to solve this problem but since it is only an approximation heats of combustion are used)

It is hoped that the above examples show how application of chemical principles in the Handling Hazardous Material course are used in real-world problems. The students are not only exposed to new concepts such as threshold limit values, flammability limits, etc., but also must review and use chemical concepts that they have not used for a year or two.

${ }^{1}$ Chemical Process Safety Fundamentals with Applications, Crowl, Daniel A. and Louvar, Joseph F.; Prentice Hall PTR, second edition, 2002.

DARYL J. DOYLE, Ph. D., Professor of Chemistry, has been on Kettering University's faculty since 1982. He earned both his B. S. and his Ph. D. from North Dakota State University in Fargo. He has published in the areas of chemical by-products of laser cutting of plastics and in laser surface treatment for adhesive bonding. In 2002 he was named Outstanding Teacher by the Kettering Alumni Association. 